\title{
A IMPORTÂNCIA DO PACTO DE SAN JOSÉ DA COSTA RICA PARA A
} PROTEÇÃO DAS FAMÍLIAS BRASILEIRAS

\author{
Gabriela Ferreira Pinto de Holanda ${ }^{1}$ \\ Flávia de Ávila ${ }^{2}$
}

\section{RESUMO}

O presente artigo objetiva analisar a importância da Convenção Americana de Direitos Humanos (Pacto de San José da Costa Rica) para a proteção das famílias brasileiras. Entretanto, antes de abordar os reflexos do citado Pacto no direito de família nacional, será feita uma reflexão sobre a sua influência na efetivação dos direitos humanos e na elaboração da Constituição Federal Brasileira, para a seguir demonstrar a sua relevância no reconhecimento das famílias plurais e democráticas, bem como, na efetivação da igualdade entre os filhos. Para isso foi utilizada como metodologia a pesquisa bibliográfica-documental, com base no método jurídico-dogmático.

Palavras-chave: Pacto de San José da Costa Rica. Constituição Federal Brasileira. Direitos Humanos. Direito de Família. Famílias plurais e democráticas. Igualdade entre os filhos.

\section{THE IMPORTANCE OF THE SAN JOSE COSTA RICA PACT FOR THE PROTECTION OF BRAZILIAN FAMILIES}

\begin{abstract}
The present article aims to analyze the importance of the American Convention on Human Rights (Pact of San José of Costa Rica) for the protection of brazilian families. However, before discussing the reflections of the aforementioned Pact on national family law, a reflection will be made on its influence on the realization of human rights and on the elaboration of the Brazilian Federal Constitution, in order to demonstrate its relevance in the recognition of plural and Democratic, as well as in ensuring equality between the children. For this, bibliographic-documentary research was used as methodology, based on the legaldogmatic method.
\end{abstract}

Keywords: Pact of San José of Costa Rica. Brazilian Federal Constitution. Human rights. Family right. Plural and democratic families. Equality between children.

\section{INTRODUÇÃO}

\footnotetext{
${ }^{1}$ Mestranda em Direito pela Universidade Federal de Sergipe, especialista em Direito Constitucional e Administrativo pelo Centro Universitário CESMAC, advogada orientadora e professora da UNINASSAU Maceió.

${ }^{2}$ Doutora em Direito pela Pontifícia Universidade Católica de Minas Gerais. Professora do Departamento de Relações Internacionais e do Programa de Pós-graduação em Direito (PRODIR) da Universidade Federal de Sergipe.
} 
A Convenção Americana de Direitos Humanos, também conhecida por Pacto de San José da Costa Rica, uma vez que foi assinada em 22 de novembro de 1969, na cidade de San José, na Costa Rica, exerceu forte influência sobre a Constituição Federal de 1988, apesar de ter sido ratificada pelo Brasil apenas no ano de 1992, através do Decreto nº 678, de 06 de novembro de 1992. Nesse contexto, o presente trabalho, por meio de pesquisa bibliográficadocumental e com base no método jurídico-dogmático descrito por Gustin e Dias (2006), tem por objetivo demonstrar a importância da referida legislação internacional para a proteção das famílias brasileiras, mas, para isso, será realizada uma análise acerca da sua relevância para a efetivação dos direitos humanos no continente americano, bem como, dos reflexos deste pacto na Constituição Federal de 1988.

Antes da Constituição de 1988, a família era essencialmente matrimonializada, patriarcal, hierarquizada e possuía como principal fim a reprodução biológica. Ou seja, para o direito, família só era aquela advinda do matrimônio, os filhos apenas teriam todos os direitos decorrentes dessa filiação se fossem fruto do casamento, e em decorrência disso, recebiam adjetivações de filhos legítimos (decorrentes do matrimônio) e filhos ilegítimos, que se dividiam em naturais (seus genitores não eram casados, mas não possuíam impedimento para tanto) e espúrios (existia impedimento para o casamento dos genitores), ainda nesse modelo familiar, a mulher se encontrava submissa ao homem, inexistindo igualdade de direitos.

Nesse cenário, percebe-se que o Pacto de 1969, apesar de ainda não ter sido ratificado pelo Brasil em 1988, terminou influenciando alguns dispositivos constitucionais, uma vez que a família adquiriu previsão expressa na Constituição, em seu artigo 226 e seguintes. Assim, com o advento da Carta Magna vigente, a família passou a ser considerada plural, apresentando-se das mais diversas formas (união estável, monoparental, anaparental, avoenga...), não mais existindo a hierarquização familiar, com a submissão da mulher ao homem, e os filhos passaram a estar desatrelados do estado civil dos pais, não importando se foram frutos do casamento ou qual a sua origem (biológica ou afetiva), todos estão em patamar de igualdade perante o direito de filiação.

Desse modo, o presente estudo se apresentará dividido em três tópicos, nos quais serão abordadas as seguintes temáticas: a influência do Pacto de San José da Costa Rica para a efetivação dos direitos humanos e sobre a Constituição Federal de 1988, os reflexos da Convenção Americana de Direitos Humanos no reconhecimento das famílias plurais e democráticas, e a igualdade entre os filhos como consequência dessa legislação internacional. 


\section{1 a influênCia do PACto de SAN JOSÉ da COSTA RICA PARA A EFETIVAÇÃO DOS DIREITOS HUMANOS E SOBRE A CONSTITUIÇÃo FEDERAL DE 1988}

A Convenção Americana de Direitos Humanos, conhecida por Pacto de San José da Costa Rica, trata-se de um tratado internacional firmado durante a Conferência Especializada Interamericana de Direitos Humanos, entre os países integrantes da Organização dos Estados Americanos, em 22 de novembro de 1969, porém apenas entrou em vigor em 18 de julho de 1969, tornando-se uma referência na proteção dos Direitos Humanos no continente americano, uma vez que se baseou na Declaração Universal dos Direitos Humanos (1948), com o fim de assegurar plena liberdade ao homem, no que se refere ao livre exercício dos seus direitos políticos, econômicos, civis, sociais e culturais.

Nesse cenário, cumpre destacar que o caráter universal dos direitos humanos surgiu com a Declaração Universal dos Direitos Humanos de 1948, denotando que esses direitos têm um sentido transcultural e trans-histórico do ser humano. Essa universalidade se sustenta no princípio de que todos os seres humanos nascem livres e iguais em dignidade e direitos. Porém, surgem críticas ao universalismo, dizendo que ele esbarra no relativismo cultural, de modo a se afirmar que deve haver um respeito à diversidade cultural que caracteriza a humanidade. Todavia esse relativismo cultural pode justificar medidas ou práticas degradantes. (MAGENDZO, 2006)

Assim, apesar dos esforços internacionais, sempre foi muito delicado assegurar a proteção dos direitos humanos no âmbito mundial, devendo-se respeitar as singularidades de cada parte do planeta, e para dar efetividade a um sistema de proteção global desses direitos inerentes aos seres humanos, é necessário conhecer a realidade cultural, política e social de cada região do globo, que muitas vezes são utilizadas como justificativas para verdadeiros atos de barbárie.

Nesse contexto, Boaventura de Souza Santos aponta a hermenêutica diatópica como um instrumento para promover a paz mundial, com a plena eficácia dos direitos humanos, através de um diálogo intercultural.

No caso de um diálogo intercultural, a troca não é apenas entre diferentes saberes mas também entre diferentes culturas, ou seja, entre universos de sentido diferentes e, em grande medida, incomensuráveis. Tais universos de 
sentido consistem em constelações de topoi fortes. Os topoi são os lugares comuns retóricos mais abrangentes de determinada cultura. Funcionam como premissas de argumentação que não se discutem dada a sua evidência ${ }^{3}$. (SANTOS, 2016).

Desse modo, além de tentar compreender a realidade cultural, política e social de cada país, para que haja uma efetiva aplicabilidade das convenções que tratam sobre Direitos Humanos na esfera mundial, indispensável que se faça uma crítica realista ao exercício da soberania, de modo que a decisão operada pelo soberano encontre freios e limites efetivos nas referidas convenções e nos demais direitos conquistados pelos homens ao longo da história da humanidade.

Uma resposta provável a esse dilema pode ser encontrada no pensamento de Hannah Arendt, citada por Celso Lafer, que propugna uma relativização do poder soberano ou uma transcendência do conceito de soberania nacional como expediente à garantia dos direitos do homem e de efetivo respeito à vida digna, independentemente do status que carregue, seja ele vinculado à noção de nacionalidade ou de cidadania.

\begin{abstract}
A construção de um mundo comum, baseado no direito de todo ser humano à hospitalidade universal (Kant) e contestado na prática pelos refugiados, pelos apátridas, pelos deslocados, pelos campos de concentração, só começaria a ser tornada viável - como aponta inicialmente Hannah Arendt em The rights of men. What are they? (1949) e desenvolve depois em The origins of totalitarianism - se o direito a ter direitos tivesse uma tutela internacional, homologadora do ponto de vista da humanidade. Nas palavras de Hannah Arendt, no fecho deste artigo de 1949: "This human right, like all other rights can exist only through mutual agreement and guarantee. Transcending the rights of the citizen - being the right of men to citizenship - this right is the only one that can and can only be guaranted by the comunity of nations". Em síntese, para usar uma linguagem contemporânea, à medida em que o direito a ter direitos se convertesse numa tema global, de governança da ordem mundial, a transcender as soberanias, ex vi da inserção operativa de uma razão abrangente da humanidade ${ }^{4}$. (LAFER, 1997)
\end{abstract}

Agamben (2004), embora não ofereça uma solução a esse dilema, observa que nunca houve no âmbito do direito público o desenvolvimento de uma teoria geral do estado de exceção, de modo que pudessem ser examinados e propostos limites, condicionamentos, balizas ao exercício do poder soberano. Obviamente, ainda que essa não seja a chave para o problema, poderia muito bem ser o pontapé inicial a uma relevante discussão sobre o assunto, compreendendo que essas violações de direitos humanos em períodos de instabilidade e

\footnotetext{
${ }^{3}$ Cf. Disponível em: <www.dhnet.org.br/direitos/militantes/boaventura/boaventura_dh.htm>.

${ }^{4}$ Cf. Disponível em: <http://dx.doi.org/10.1590/S010340141997000200005>.
} 
insegurança não guardam pertinência apenas a uma questão política, mas também, e principalmente, a uma questão concernente à ciência jurídica.

Quiçá, a partir de um exame crítico sobre o poder soberano e da assunção pelo Direito de parcela de responsabilidade sobre a resolução dos conflitos decorrentes de seu exercício indiscriminado, será possível imaginar um processo de "descoisificação" do ser humano, de modo que a vida digna seja o valor a ser considerado em todos os propósitos adotados no plano das decisões políticas.

Desse modo, apesar de se deparar com a resistência de alguns países, os quais se valem do seu poder soberano para justificar supostas práticas culturais, o Pacto de San José da Costa Rica, em seus 81 artigos, visa resguardar, nos países americanos, os direitos fundamentais da pessoa humana (direito à vida, à dignidade, à liberdade, à educação, etc.), além de tratar das garantias judiciais, da liberdade de consciência, de religião, de pensamento e de expressão, proibir a escravidão e a servidão humana, bem como, convencionar acerca da liberdade de associação e da proteção à família.

Apesar do pacto em estudo apenas ter sido recepcionado pelo Brasil no ano de 1992, possuindo validade de lei ordinária, caso não entrasse em conflito com a Constituição Federal, ele exerceu certa influência sobre esta.

Todavia, com a promulgação da Emenda Constitucional no. 45 de 2004, os tratados referentes aos direitos humanos entraram em vigor imediatamente e foram equiparados às normas constitucionais, porém deveriam ser aprovados em dois turnos, por, ao menos, três quintos dos votos na Câmara dos Deputados e no Senado Federal.

Desse modo, apesar da Convenção Americana de Direitos Humanos apenas ter recebido o status de norma constitucional com a EC 45/2004, a Constituição Federal de 1988, desde a sua elaboração sofreu influência indireta dela, o que se reflete na constitucionalização de alguns direitos que somente encontravam guarida na esfera privada, os quais passaram a ganhar proteção constitucional, a exemplo do direito de família, o que será estudado de forma mais aprofundada nos tópicos seguintes.

\section{OS REFLEXOS DA CONVENÇÃO AMERICANA DE DIREITOS HUMANOS NO RECONHECIMENTO DAS FAMÍLIAS PLURAIS E DEMOCRÁTICAS NO BRASIL}


O sistema civilista codificado em 1916, teve como principal fonte as Ordenações Filipinas do Império, mas, ainda assim, inovou no tocante à codificação do Direito de Família Brasileiro, que até então inexistia regulamentação.

O modelo de família, doravante sob a regência do supramencionado Código Civil, excluía todas as entidades familiares que não fossem constituídas por meio do casamento, ou seja, o casamento era a única forma de constituir uma família legítima.

O diploma legal de 1916 identificou as concepções de famílias como aquelas instituídas pelo casamento entre homem e mulher. O retromencionado Código Civil atribuía ao marido a chefia da sociedade conjugal, assim a mulher configurava como mera colaboradora e auxiliar dos encargos familiares, conforme preceitua o caput do artigo 240 do referido código:

Art. 240 - A mulher, com o casamento, assume a condição de companheira, consorte e colaboradora do marido nos encargos da família, cumprindo-lhe velar pela direção material e moral desta. (Redação dada pela Lei n ${ }^{\circ} 6.615$, de 1977).

Desse modo, percebe-se que na vigência do Código Civil de 1916 a família era essencialmente matrimonializada, hierarquizada, biológica (seu principal fim era a procriação) e patriarcal (o homem era o detentor do pátrio poder ${ }^{5}$ ).

A família contemporânea fundada na busca da realização pessoal de seus membros rompe definitivamente com aquele modelo de família matrimonializada, patriarcal, hierarquizada, decorrentes do Código Civil de 1916. Durante a vigência do aludido diploma legal as pessoas se uniam com vistas à formação de patrimônio para sua posterior transmissão aos herdeiros, pouco importando os laços afetivos.

Nesse sentido, acerca dos pilares das famílias atuais, Farias e Rosenvald (2011, p. 5) destacam que "os referenciais da família contemporânea são: o afeto, a ética, a solidariedade recíproca entre seus membros e na preservação da dignidade deles". No que tange ao formato e finalidades adotadas pelas famílias contemporâneas, ainda complementam:

[...] a família deixa de ser compreendida como núcleo econômico e reprodutivo (entidade de produção), avança-se para uma compreensão socioafetiva (como expressão de uma unidade de afeto e entre-ajuda), e

\footnotetext{
5 Art. 380. Durante o casamento compete o pátrio poder aos pais, exercendo-o o marido com a colaboração da mulher. Na falta ou impedimento de um dos progenitores, passará o outro a exercê-lo com exclusividade.

Parágrafo único. Divergindo os progenitores quanto ao exercício do pátrio poder, prevalecerá a decisão do pai, ressalvado à mãe o direito de recorrer ao juiz para solução da divergência. (Código Civil de 1916)
} 
surgem, naturalmente, novas representações sociais, novos arranjos familiares. Abandona-se o casamento como ponto referencial necessário, para buscar a proteção e o desenvolvimento da personalidade do homem. É a busca da dignidade humana, sobrepujando valores meramente patrimoniais. (Op. cit., p. 6-7).

Assim, tem a ruptura definitiva com um modelo necessariamente heteroparental e o reconhecimento de novos grupos familiares, como as famílias monoparentais, entidade formada por um dos ascendentes e seus descendentes, a união estável e em outros núcleos fundados no afeto e na solidariedade. Esta preocupação com a proteção dos diferentes arranjos familiares está presente no artigo 226 da Constituição Federal.

Com a análise do artigo 226 da CF/88 constata-se que seu caput ${ }^{6}$ traduz o disposto no inciso 1 do artigo 17 do Pacto de San José da Costa Rica ${ }^{7}$, que é a identificação da família como núcleo da sociedade, uma vez que é através dela que os ensinamentos para formação de cidadãos são repassados. O que evidencia uma importante função social da família, merecendo, por isso, uma proteção maior por parte do Estado.

Contudo, nem todos os parágrafos e incisos do citado artigo 226 são taxativos, uma vez que todo e qualquer núcleo familiar fundado no afeto, merece especial proteção do Estado, de forma que desproteger inúmeros agrupamentos familiares não contemplados no referido artigo colidiria com os princípios da dignidade da pessoa humana e da igualdade substancial.

Nesse cenário, percebe-se que o modelo igualitário da família atual constitucionalizada é totalmente contrário ao modelo autoritário adotado pelo Código Civil de 1916, visto que os artigos 226 ao 230 foram fortemente influenciados por uma mudança pragmática fundamentada no consenso, na solidariedade e no respeito à dignidade das pessoas que integram as novas formações familiares. (LÔBO, 2011).

Nesse sentido, Maria Berenice Dias (2010) destaca que é necessário ter uma visão pluralista da família, abrigando os mais diversos arranjos familiares, devendo-se buscar o elemento que permite enlaçar no conceito de entidade familiar todos os relacionamentos que têm origem em um elo de afetividade, independentemente de sua conformação.

Nos dias de hoje, o que identifica a família não é nem a celebração do casamento nem a diferença de sexo do par ou envolvimento de caráter

\footnotetext{
${ }_{7}^{6}$ Art. 226. A família, base da sociedade, tem especial proteção do Estado.

7 Art. 17, inciso I: A família é o núcleo natural e fundamental da sociedade e deve ser protegida pela sociedade e pelo Estado.
} 
sexual. O elemento distintivo da família, que a coloca sob o manto da juridicidade, é a presença de um vínculo afetivo a unir pessoas com identidade de projetos de vida e propósitos comuns, gerando comprometimento mútuo. (Op. cit., p.42).

Ante o exposto, constata-se que após a Constituição Federal de 1988, sob influência do Pacto de San José da Costa Rica, as famílias se tornaram democráticas, marido e mulher possuem os mesmos direitos e deveres, assim, o pátrio poder passou a ser denominado de poder familiar ${ }^{8}$, essa igualdade de direitos e deveres entre os gêneros já podia ser visualizada nos incisos 2, 3 e 4 do artigo $17^{9}$ do aludido pacto, os quais foram sintetizados de forma expressa no parágrafo $5^{\circ}$ do artigo 226 da nossa Carta Magna, o qual dispõe que: "Os direitos e deveres referentes à sociedade conjugal são exercidos igualmente pelo homem e pela mulher".

Também com o advento da Constituição Federal vigente, a qual, na sua elaboração sofreu influência da Convenção Americana de Direitos Humanos de 1969, especificamente do seu artigo 17, as formações familiares deixaram de ser essencialmente matrimonializadas e passaram a ser plurais, podendo-se destacar algumas diferentes entidades familiares, como: a matrimonial, decorrente da união estável, homoafetiva, monoparental, anaparental, reconstituída ou mosáico e eudemonista, as quais serão abordadas de forma mais detalhada a seguir.

\subsection{Família matrimonial}

A família matrimonial é caracterizada pela união entre um homem e uma mulher através de um sacramento indissolúvel e que tem como finalidade a procriação. Como já

\footnotetext{
${ }^{8}$ Art. 1.630. Os filhos estão sujeitos ao poder familiar, enquanto menores.

Art. 1.631. Durante o casamento e a união estável, compete o poder familiar aos pais; na falta ou impedimento de um deles, o outro o exercerá com exclusividade.

Parágrafo único. Divergindo os pais quanto ao exercício do poder familiar, é assegurado a qualquer deles recorrer ao juiz para solução do desacordo. (Código Civil de 2002)

${ }^{9} 2$. É reconhecido o direito do homem e da mulher de contraírem casamento e de constituírem uma família, se tiverem a idade e as condições para isso exigidas pelas leis internas, na medida em que não afetem estas o princípio da não-discriminação estabelecido nesta Convenção.

3. O casamento não pode ser celebrado sem o consentimento livre e pleno dos contraentes.

4. Os Estados-partes devem adotar as medidas apropriadas para assegurar a igualdade de direitos e a adequada equivalência de responsabilidades dos cônjuges quanto ao casamento, durante o mesmo e por ocasião de sua dissolução. Em caso de dissolução, serão adotadas as disposições que assegurem a proteção necessária aos filhos, com base unicamente no interesse e conveniência dos mesmos.
} 
explanado, até a entrada em vigor da atual Constituição, o casamento era a única forma admissível de formação familiar.

Sob a justificativa de manter a ordem social, tanto o Estado como as igrejas acabaram controlando a vida das pessoas. Na tentativa de regular as relações afetivas, assumiram postura conservadora para preservar um estrito padrão de moralidade.

Só era reconhecida a família constituída pelo casamento. O homem exercia a chefia da sociedade conjugal, sendo merecedor de respeito, devendo-lhe a mulher e os filhos obediência. A finalidade essencial da família era a conservação do patrimônio, precisando gerar filhos como força de trabalho. (DIAS, 2010, p. 45).

O Estado sempre resistiu em admitir vínculos de convivência fora do casamento. Apesar de todo repúdio da legislação, vínculos afetivos começaram a surgir. Esse prestígio à família extramatrimonial atende aos interesses do Estado, pois delega a ela formação dos seus cidadãos, a busca da felicidade, sem se sentirem presas em estruturas preestabelecidas.

\subsection{Família decorrente da união estável}

A família informal tratava-se de uma relação classificada como concubinato, sendo também denominada de relações adulterinas, onde os filhos deste relacionamento eram discriminados diante da família matrimonial.

A lei emprestava juridicidade apenas à família constituída pelo casamento, vedando quaisquer direitos às relações denominadas adulterinas ou concubinárias. Entretanto, isso não coibiu o surgimento de relacionamentos sem respaldo legal. A eterna busca da felicidade fazia com que os egressos de vínculos desfeitos constituíssem novas famílias.

A concubina, como era chamada, não tinha qualquer direito com o fim dessa união, no máximo ela recebia uma indenização por serviços domésticos prestados. Quando elas começaram a bater às portas do judiciário, os juízes foram forçados a criar alternativas para evitar injustiças cometidas contra elas.

A legislação infraconstitucional que veio a regular essa nova espécie de família acabou praticamente copiando o modelo oficial do casamento. O código civil impõe requisitos para o reconhecimento da união estável, gera deveres e cria direitos aos conviventes. Assegura alimentos, estabelece o regime de bens e garante ao convivente direitos sucessórios. (Op. cit., p.47). 
O reconhecimento pela Constituição da união estável como família, em seu art. 226, parágrafo $3^{\circ}$, foi fruto de um grande avanço. Mas isso foi apenas o início, uma vez que atualmente percebe-se quase que uma paridade com os direitos advindos do casamento.

\subsection{Família homoafetiva}

Atualmente com o reconhecimento da união estável e do casamento entre pessoas do mesmo sexo, surge uma nova modalidade de família, no caso a família homoafetiva, ainda vista com certo preconceito pela sociedade.

Na família do século XXI já há uma preponderância da afetividade sobre a biologicidade e com isto é preciso o avanço jurídico para o reconhecimento das famílias homoafetivas, é tanto que o ex-ministro do Supremo Tribunal Federal, Carlos Ayres Britto, equiparou as relações entre pessoas do mesmo sexo às uniões estáveis. Segundo o ex-ministro "Tudo que não está juridicamente proibido, está juridicamente permitido. A ausência de lei não é ausência de direito, até porque o direito é maior do que a lei" (BRITO, 2011) ${ }^{10}$. De modo a confirmar tal posicionamento, a Resolução n. $175^{11}$, de 14 de maio de 2013, do Conselho Nacional de Justiça estabeleceu que nenhum juiz ou tribunal podem se recusar a celebrar o casamento entre pessoas do mesmo sexo, ou a conversão da união homoafetiva em casamento.

Na Constituição Federal a proteção das uniões homoafetivas já é assegurada pelos seguintes princípios: Da dignidade humana (art. $1^{\circ}$, inciso III), da igualdade substancial (arts. $3^{\circ}$ e $5^{\circ}$ ), da não discriminação, inclusive pela opção sexual (art. $5^{\circ}$ ) e do pluralismo familiar (art. 226) o que consagra diferentes modelos de entidades familiares.

Logo, as uniões homoafetivas são entidades familiares autônomas, merecendo especial proteção ao lado do casamento, da união estável, da família monoparental, dentre outros núcleos.

\subsection{Família monoparental}

\footnotetext{
${ }^{10}$ Cf. Disponível em: <http://www.conjur.com.br/2011-mai-06/leia-voto-ministro-ayres-britto-reconhece-uniaohomoafetiva>.

${ }^{11}$ Art. $1^{\circ}$ É vedada às autoridades competentes a recusa de habilitação, celebração de casamento civil ou de conversão de união estável em casamento entre pessoas de mesmo sexo.
} 
A família monoparental é aquela constituída por um dos genitores e a sua prole, sendo reconhecida expressamente pelo artigo 226, parágrafo $4^{\circ}$, da Constituição Federal, o qual tem a seguinte redação: "entende-se, também, como entidade familiar a comunidade formada por qualquer dos pais e seus descendentes" (BRASIL, 2016).

Desse modo, constata-se que esse arranjo familiar é formado por pessoas sozinhas, sejam solteiras, descasadas, viúvas que vivem com sua prole sem a presença de um parceiro afetivo. É o exemplo da mãe solteira que vive com a sua filha ou mesmo de um pai viúvo que se mantém com sua prole.

\subsection{Família anaparental}

A família anaparental trata-se de uma entidade familiar onde há a convivência entre parentes ou entre pessoas, mesmo inexistindo qualquer conotação sexual, a exemplo da convivência de duas irmãs sob o mesmo teto.

Para Dias (2010, p. 48) "a convivência entre parentes ou entre pessoas ainda que não parentes, dentro de uma estruturação com identidade de propósito, impõe o reconhecimento da existência de entidade familiar batizada com o nome de família parental ou anaparental". Esta relação é firmada pela parceria entre os que convivem, portanto merece uma proteção constitucional e o reconhecimento da sociedade.

\subsection{Família reconstituídas ou mosaico}

Com o reconhecimento e facilitação do divórcio e da separação surge uma nova expressão de família: reconstituída ou mosaico. Nesta relação familiar se constrói um núcleo reorganizado de filhos provenientes de outros relacionamentos ou casamentos, já trazidos pelos pais separados ou divorciados.

A especificidade decorre da peculiar organização do núcleo, reconstruído por casais onde um ou ambos são egressos de casamentos ou uniões anteriores. Eles trazem para a nova família seus filhos e, muitas vezes, têm filhos em comum. É a clássica expressão: os meus, os teus, os nossos... (Op. cit., p. 51). 
São entidades familiares decorrentes de uma recomposição afetiva, nas quais pelo menos um dos interessados traz filhos decorrentes de um relacionamento familiar anterior. É o clássico exemplo da madrasta e padrasto de filho advindo de outra união ou casamento.

Essa formação familiar é consequência da facilitação do divórcio e da aceitação de novos relacionamentos após o rompimento de um matrimônio ou de uma união estável.

\subsection{Eudemonista:}

A família decorrente do casamento vem cada vez mais cedendo espaço para o reconhecimento das relações afetivas na busca da felicidade, do amor e da solidariedade, e isto contribui para o reconhecimento de um novo modo de se formar uma família - a eudemonista.

A absorção do princípio eudemonista pelo ordenamento altera o sentido da proteção jurídica da família, deslocando-o da instituição para o sujeito, como se infere da primeira parte do $\$ 8^{\circ}$ do art. 226 da CF: o Estado assegurará a assistência à família na pessoa de cada um dos componentes que a integra. (Op. cit., p. 54).

O eudemonismo é a doutrina da busca da felicidade e realização de seus membros, onde o Estado não interfere na vida das pessoas. O formato hierárquico da família cedeu lugar à democratização, onde as relações são muito mais de igualdade, liberdade e respeito mútuo.

Com todos estes formatos de família, o direito das famílias está cada vez mais se transformando diante das suas aplicações, e passa a recorrer à doutrina e à jurisprudência para nortear o direito ao reconhecimento dessas novas formações familiares.

\section{A PROTEÇÃO E A IGUALDADE ENTRE OS FILHOS COMO CONSEQUÊNCIA DO PACTO DE SAN JOSÉ DA COSTA RICA}

O Pacto de San José da Costa Rica inova na proteção e promoção da igualdade entre os filhos, ao assegurar no inciso 4 do artigo 17 a adoção de disposições que proporcionem uma proteção especial aos filhos, de modo a preservar os seus interesses e conveniências. Já no inciso $5^{12}$ do mesmo artigo são reconhecidos direitos iguais para os filhos nascidos dentro 5. A lei deve reconhecer iguais direitos tanto aos filhos nascidos fora do casamento, como aos nascidos dentro
do casamento. 
e fora do casamento, o que significa que a condição plena de filho não se sujeitaria ao estado civil dos pais.

Apesar do pacto ter entrado em vigor desde o ano de 1978, ele só foi ratificado pelo Brasil em 1992. Contudo, a Constituição Federal de 1988 já expressou no parágrafo $6^{\circ}$ do artigo $227^{13}$, a extinção da adjetivação de filhos, ou seja, todos os filhos passaram a ser iguais para todos os fins de direito, independentemente da sua origem ou se foram frutos ou não do casamento.

Mas antes da Constituição de 1988 esse cenário era bem diferente, os filhos recebiam adjetivos que os distinguiam pela sua origem ou por ter sido fruto ou não do casamento. Somente eram considerados legítimos e possuíam todos os direitos decorrentes da filiação aqueles que eram provenientes do casamento e de forma biológica, os que não vinham do matrimônio eram denominados de ilegítimos, que ainda se dividiam em naturais, que eram aqueles que os pais não eram casados, mas não tinham impedimento para tanto, e espúrios, que era quando os genitores estavam impedidos de se casarem, seja por já serem comprometidos (espúrios adulterinos) ou por haver uma relação de parentesco entre eles (espúrios incestuosos).

Quanto à adoção, ela era realizada por escritura pública, sem a interferência do Estado e tinha como finalidade atender os interesses de casais inférteis, inclusive a redação original do artigo 368 do Código Civil de 1916 previa que apenas as pessoas maiores de 50 (cinquenta) anos e sem prole legítima poderiam adotar. Nesses casos os filhos adotivos somente teriam todos os direitos decorrentes da filiação se os seus pais não tivessem filhos biológicos (legítimos), pois caso contrário, só teriam direito à herança no equivalente à metade da cota parte de um filho legítimo.

Mas essas previsões legislativas preconceituosas quanto à filiação ficaram no passado, visto que desde o Pacto de San José da Costa Rica a igualdade entre os filhos e a atribuição de uma proteção especial a eles, em caso de divórcio ou separação entre os seus genitores, já eram asseguradas, e passou a influenciar a elaboração de dispositivos normativos nacionais.

Nesse cenário, diante da paridade entre os filhos, a filiação afetiva tem ganhado espaço e, em alguns casos, tem prevalecido ante a puramente biológica, pois se antes o vínculo biológico era o parâmetro fundamental, se tudo era resolvido com a abertura do envelope do exame de DNA, posteriormente esse passou a ser somente um dos aspectos a serem

${ }^{13} \S 6^{\circ}$ Os filhos, havidos ou não da relação do casamento, ou por adoção, terão os mesmos direitos e qualificações, proibidas quaisquer designações discriminatórias relativas à filiação. 
considerados. Passou-se a dar valor também ao afeto e, ainda à dignidade e honra dos envolvidos na demanda, que, por vezes, passavam pela difícil situação de deixar de ser filho daquele que sempre foi tido como seu pai, ou, em caso reverso, deixar de ser pai daquele a quem sempre dedicou cuidados e carinho.

$\mathrm{Na}$ visão de Póvoas (2012, p. 12) surgia então, "a filiação sócio-afetiva ${ }^{14}$, onde a inexistência de vínculo biológico não era o principal fundamento da ação", a causa de pedir baseia-se na existência de afeto entre as partes e ainda na aplicação do princípio da dignidade da pessoa humana.

Nesse cenário, inicia-se a discussão acerca da figura da multiparentalidade ou pluriparentalidade, a qual é conceituada por Farias e Rosenvald (2011, p. 621) como a

[...] possibilidade de concomitância, de simultaneidade, na determinação da filiação de uma mesma pessoa. Isto é, advogam a possibilidade de uma pessoa ter mais de um pai e/ou mais e uma mãe simultaneamente, produzindo efeitos jurídicos em relação a todos eles a um só tempo.

Partindo-se do pressuposto da possibilidade de coexistência da paternidade biológica com a paternidade socioafetiva, tem-se que a sua viabilidade vai além de um simples direito, mas trata-se de uma obrigação constitucional, uma vez que seu reconhecimento proporciona a efetivação dos direitos fundamentais dos seres envolvidos nessas relações, em especial, a dignidade e afetividade. (PÓVOAS, 2012).

A evolução natural dos vários núcleos familiares impossibilita o reconhecimento como entidade familiar apenas daquilo que o legislador estabelece. Além da família tradicional, formada por marido, esposa e filhos, é reconhecido constitucionalmente o convívio entre pessoas de sexos diferentes como união estável, a existência da família monoparental, e de formações familiares construídas pelo casamento ou união entre pessoas do mesmo sexo, as quais já foram devidamente apresentadas anteriormente.

Diante de vários arranjos familiares e da igualdade entre os filhos, as famílias multiparentais passaram a ser reconhecidas por muitos tribunais pátrios desde o ano de 2012, e no ano de 2016 ganhou reconhecimento do Supremo Tribunal Federal através do julgamento do RE 898060-SC. Assim, vale realçar que o artigo 226 da Constituição Federal de 1988 não

\footnotetext{
14 A palavra "sócio-afetiva" está de acordo com a escrita do autor. Em outros momentos ela está escrita conforme a nova ortografia, socioafetiva.
} 
encerra uma enumeração taxativa, mas sim exemplificativa, pois se a liberdade de constituição de família é um direito fundamental, não pode o estado limitar as suas formas.

Fazendo uma análise acerca do melhor interesse da criança, seria muito mais benéfico para ela, que em vez de ter um pai e uma mãe para lhe dar carinho, amor e atenção, poder ter mais de um deles. E nesses casos, não será preciso fazer uma escolha entre um e outro genitor, visto que a solução mais adequada e justa é o reconhecimento da multiparentalidade, ou seja, tanto o pai/mãe genético quanto os afetivos seriam registrados como genitores, com todas as consequências decorrentes da relação que entre eles se estabelece com a filiação. A família tradicional biparental começa a dar lugar para uma família pluriparental.

Dentro desse contexto, percebe-se que ao promover a construção de famílias democráticas, igualitárias e fundadas no afeto, ao assegurar proteção especial para esse núcleo essencial da sociedade, e ao reconhecer a igualdade entre os filhos e a sua necessária proteção, o Pacto de San José da Costa Rica serviu de base para o surgimento e aceitação pelo Estado de vários arranjos familiares, os quais também passam a fazer jus a uma proteção estatal.

\section{CONCLUSÃO}

A Convenção Americana de Direitos Humanos, também conhecida como Pacto de San José da Costa Rica, de 1969, foi um importante instrumento para efetivação dos direitos humanos nos países americanos, apesar de ser uma difícil missão promover a plena aplicabilidade desses direitos em todos os países, visto que muitas vezes eles entram em choque com a realidade cultural, econômica, política e com o poder soberano das nações. Foi possível perceber que com a difusão de relevantes legislações internacionais e com o uso de técnicas específicas, a exemplo da hermenêutica diatópica sustentada por Boaventura de Souza Santos, aos poucos, a proteção dos direitos inerentes aos seres humanos pode se tornar uma realidade em todos os países.

Apesar do Brasil somente ter aderido ao aludido pacto em 1992, e ele ter adquirido o status de norma constitucional apenas com a Emenda Constitucional $n^{\circ} .45$ de 2004, na Constituição Federal de 1988 já se visualizava a forte influência da Convenção Americana de Direitos Humanos, ao serem positivados direitos fundamentais já previstos na referida legislação internacional. No caso em estudo, foram destacados os reflexos do pacto na proteção das famílias brasileiras. 
Nesse cenário, foi realçado que o artigo 17 do Pacto de San José da Costa Rica estabelece a proteção à família como dever da sociedade e do Estado, por considerá-la o núcleo natural e fundamental da sociedade. Para isso estabelece condições de igualdade para homens e mulheres no que se refere ao consentimento para a constituição do casamento, e para os direitos e deveres decorrentes dele, o que termina por estabelecer uma família com características democráticas. Quanto aos filhos, a Convenção assegura direitos iguais para os que forem provenientes do casamento ou de relação fora dele, e dispõe que no rompimento do matrimônio, a prole deve receber uma maior proteção, com o fim de atender os seus interesses e conveniências.

O previsto no artigo 17 da Convenção foi reproduzido de forma mais ampla e aprofundada pelos artigos 226 ao 230 da Constituição Federal de 1988, o que serviu de terreno fértil para promover o reconhecimento e a proteção de formações familiares plurais, fundadas no afeto, na igualdade entre homens e mulheres e na paridade de direitos entre os filhos.

Assim, além do surgimento dos mais diversos tipos de arranjos familiares (famílias matrimonializadas, monoparental, anaparental, homoafetiva, resconstituída, entre outras), com a igualdade de direitos entre os filhos, independente da sua origem ou se foi oriundo ou não do casamento, a multiparentalidade passou a ser reconhecida pelo Supremo Tribunal Federal, o que proporciona a coexistência de mais de um pai ou mais de uma mãe, seja de origem genética ou afetiva, no registro do filho, possuindo os mesmos direitos e deveres.

\section{REFERÊNCIAS}

AGAMBEN, G. Homo Sacer: o poder soberano e a vida nua I. Belo Horizonte: Ed. UFMG, 2004.

BRASIL. Constituição da República Federativa do Brasil (1988). Planalto. Disponível em: http://www.planalto.gov.br/ccivil_03/constituicao/ConstituicaoCompilado.htm. Acesso em: 27 nov. 2016.

Lei $n^{\circ}$. 3.071, de $1^{\text {o }}$ de janeiro de 1916. Código Civil de 1916. Planalto. Disponível em: <https://www.planalto.gov.br/ccivil_03/leis/L3071.htm>. Acesso em: 27 nov. 2016.

Lei no . 10.406, de 10 de janeiro de 2002. Código Civil de 2002. Planalto.

Disponível em: <http://www.planalto.gov.br/ccivil_03/leis/2002/L10406.htm>. Acesso em: 27 nov. 2016. 
BRITTO, Carlos Ayres. Constituição de família. Revista Consultor Jurídico. Publicada em: 6 mai. 2011. Disponível em: <http://www.conjur.com.br/2011-mai-06/leia-voto-ministroayres-britto-reconhece-uniao-homoafetiva>. Acesso em: 27 nov. 2016.

CONVENÇÃO Americana de Direitos Humanos (Pacto de San José da Costa Rica), 1980. In: Associação dos Magistrados Brasileiros (AMB). Disponível em <http://www.amb.com.br/fonavid/Legislacao_Pacto_San_Jose_da_Costa_Rica__1969[1].pdf>. Acesso em 27 nov. 2016.

DECLARAÇÃO Universal dos Direitos Humanos, 1948. In: Supremo Tribunal Federal (STF). Disponível em < http://www.stf.jus.br/portal/cms/verNoticiaDetalhe.asp?idConteudo=100499>. Acesso em: 27 nov. 2016.

DIAS, Maria Berenice. Manual de Direito das Famílias. São Paulo: Editora Revista dos Tribunais, 2010.

FARIAS, Cristiano Chaves de; ROSENVAL, Nelson. Direito das Famílias. 3. ed. ver ampliada e atual. Rio de Janeiro: Lumen Juris, 2011.

GUSTIN, Miracy; DIAS, Maria Tereza Fonseca. (Re)pensando a pesquisa jurídica: teoria e prática. 2. ed. Belo Horizonte: Del Rey, 2006.

LAFER, Celso. A reconstrução dos direitos humanos: a contribuição de Hannah Arendt. Estud. av., v.11, n.30, São Paulo, maio/ago. 1997. Disponível em:

<http://dx.doi.org/10.1590/S010340141997000200005>. Acesso em: 30 nov. 2016.

LÔBO, Paulo. Direito Civil: famílias. 4.ed. São Paulo: Saraiva, 2011.

MAGENDZO, Abraham. Educación en Derechos Humanos: un desafío para los docentes de hoy. Santiago, Chile: Editorial LOM, 2006.

PÓVOAS, Maurício Cavallazi. Multiparentalidade. A possibilidade de múltipla filiação registral e seus efeitos. Florianópolis: Conceito Editorial, 2012

SANTOS, Boaventura de Souza. Por uma concepção multicultural de Direitos Humanos. Disponível em: <www.dhnet.org.br/direitos/militantes/boaventura/boaventura_dh.htm>. Acesso em: 27 nov. 2016. 